\title{
Crescimento e absorção de macronutrientes na cultura da melancia no estado de Pernambuco
}

\section{Growth and macronutrient absorption in the watermelon crop in the State of Pernambuco}

\author{
Pedro Aguiar Neto ${ }^{1}$; Raimunda Ariádna Gomes de Souza ${ }^{2}$; Patricio Borges Maracajá ${ }^{3}$; Aline Carla de Medeiros ${ }^{4}$ \\ Thiago Alves Pimenta ; Tiago Silva Lima
}

\begin{abstract}
Resumo: Objetivou-se avaliar o crescimento e acúmulo de macronutrientes por cultivares de melancia no estado de Pernambuco. O trabalho foi conduzido na estação experimental Bebedouro (Petrolina-PE) pertencente à EMBRAPA Semiárido, no período de setembro a dezembro de 2009. O solo da área experimental foi classificado como argilosolo vermelho-amarelo eutrófico (EMBRAPA, 1999). O delineamento utilizado foi em blocos casualizados completos, com quatro repetições em esquema fatorial 2x5. Os tratamentos resultaram da combinação de duas cultivares de melancia (Quetzale e Shadow) e cinco épocas de coletas: 15, 25, 35, 45 e 55 dias após o transplantio. Em cada coleta foram utilizadas três plantas por repetição. A unidade experimental para o experimento foi constituída por três fileiras de plantas de $10,5 \mathrm{~m}$ de comprimento, com espaçamento de 2,0 x0,50m perfazendo um total de $63,0 \mathrm{~m}^{2}$. As coletas de plantas foram realizadas na fileira central. As cultivares Quetzale e Shadow apresentaram crescimento inicial lento, intensificando a partir dos 25 dias após o transplantio. Maiores incrementos na matéria seca total da parte aérea e do fruto ocorreram no período de 45 a 55 dias após o transplantio. Na colheita, a parte aérea e o fruto da cultivar Quetzale apresentaram os maiores acúmulos de 52\%. E os macronutrientes foram absorvidos pelas cultivares na seguinte ordem: $\mathrm{K}>\mathrm{N}>\mathrm{Ca}>\mathrm{P}>\mathrm{Mg}$.
\end{abstract}

Palavras-chave: Citrullus lanatus Thunb.; cultivar Shadow ; cultivar Quetzale

\begin{abstract}
This study aimed to evaluate the growth and accumulation of macronutrients by watermelon cultivars in the state of Pernambuco. The experiment was conducted in the experimental station of Bebedouro (Petrolina-PE) which belongs to EMBRAPA Semiarid from September to December in 2009. The soil of experimental area was classified as red-yellow eutrophic claylish soil.The experimente was done in a complete randomized with four replications in a factorial scheme $2 \times 5$. The treatments resulted from the combination os two cultivars of watermelon (Quetzale and Shadow) and five collects: 15, 25, 35, 45 and 55 days after transplanting. Three plants were used per repetition in each collect. The experimental unit consisted of three rows of plants with $10,5 \mathrm{~m}$ long, spaced by $2,0 \times 0,50 \mathrm{~m}$ making up $63,0 \mathrm{~m}^{2}$. The plants were collected from the central row. The cultivars Quetzale and Shadow presented slow initial growth, improving from the twenty-fifth day after transplanting. The largest increases in the total dry matter of the aerial part and fruit happened between 45 and 55 days after transplanting. At harvest, the aerial part and the fruit of the cultivar Quetzale presented the largest accumulations, in a total of $52 \%$. And the macronutrients were absorbed by both cultivars in the following order: $\mathrm{K}>\mathrm{N}>\mathrm{Ca}>\mathrm{P}>\mathrm{Mg}$.
\end{abstract}

Keywords : Citrullus lanatus Thunb., grow crops Shadow, grow crops Quetzale

\footnotetext{
*Autor para correspondência

Recebido para publicação em 15/08/2016; aprovado em 29/09/2016

${ }^{1}$ Porf. D. Sc. do IFCE-Campus Crato - CE. E-mail: pedroaguiarneto@terra.com.br Fone: (88) 999654701;

${ }^{2}$ Professora do IFCE-Campus Crato, Licenciada em Agropecuária e Letras pela UFAM e Mestre em Ciências da Educação pela Universidade Del Pacífico.

E-mail: r_ariádna_gs@yahoo.com.br

${ }^{3}$ Prof. D. Sc. do PPGSA /UAGRA / CCTA / UFCG - Pombal - PB - E-mail: patriciomaracaja@gmail.com

${ }^{4}$ Doutoranda do Programa de pós-graduação em engenharia de processos (PPGEP) da UFCG - Campina Grande - PB E-mail alinecarla.edu@ gmail.com

${ }^{5}$ Gradudandos do curso de Agronomia da Universidade Federal de Campina Grande, Campus Pombal-PB, E-mail: tpimenta62@gmail.com; lima_tiago92@outlook.com
} 


\section{INTRODUÇÃO}

A melancia tem grande importância sócio-econômica por ser cultivada principalmente por pequenos agricultores. Tem fácil manejo e menor custo de produção quando comparada a outras hortaliças, constituindo-se em importante cultura para o Brasil pela demanda intensiva de mão-de-obra rural (ROCHA, 2010). Do ponto de vista socioeconômico, gera renda e empregos, e ajuda a manter o homem no campo, além de ter um bom retorno econômico para o produtor. Dados da FAO (2010) apontam como maiores produtores mundiais de melancia, em ordem decrescente: China, Turquia, Irã, Brasil, Estados Unidos e o Egito, correspondendo a $87 \%$ da produção mundial, sendo que a produção foi de cerca de 79,5 milhões de toneladas, com a china participando com 71,3\%. Araújo, J. e Araújo E. (2008) destaca a atual importância da melancia como uma das principais frutas em volume de produção mundial e também estando dentre os dez produtos hortifrutícolas mais exportados, com um mercado estimado em mais de 1,7 milhões de toneladas por ano.

O Brasil tem uma área plantada de $96.477 \mathrm{ha}^{-1}$, com uma produção de 2.052.928 toneladas, rendimento médio $21.622 \mathrm{~kg} \mathrm{ha}^{-1}$ e um valor de produção de $\mathrm{R} \$ 823.755 .000$, que representa $4 \%$ do valor da produção das principais frutíferas produzidas no Brasil (IBGE, 2010). No nordeste, para o mesmo período, a melancia ocupou uma área plantada de 37.201 ha, com uma produção de 701.213 toneladas, apresentando um rendimento médio de $20.218 \mathrm{~kg} \mathrm{ha}^{-1}$, e um valor de produção da ordem de $\mathrm{R} \$$ 245.223.000. Por outro lado, o RN, ainda no mesmo período, possuía uma área plantada de 3.063 ha, produzindo cerca de 76.872 toneladas, tendo um rendimento médio de $26.471 \mathrm{~kg} \mathrm{ha}^{-1}$ e um valor de produção de R\$ 28.528.000. A melancia apresentou acréscimo de $16,1 \%$ no valor da produção quando comparada com o mesmo período do ano anterior (IBGE, 2010).

As regiões Nordeste e Sul são as principais regiões produtoras de melancia no Brasil, contribuindo, respectivamente com $35,95 \%$ e $26,93 \%$ do total da produção nacional. Os estados com maior produção são Rio Grande do Sul, Bahia e Goiás, representando, respectivamente 16,9\%; $16,48 \%$ e $13,1 \%$ da produção nacional (IBGE, 2010). Os estados brasileiros com maior produtividade nacional são o Ceará (41.148 kg ha $\left.{ }^{-1}\right)$, Goiás (34.654 kg ha $\left.{ }^{-1}\right)$, São Paulo (28.260 $\left.\mathrm{kgha}^{-1}\right)$, Rio Grande do Norte $\left(26.471 \mathrm{~kg} \mathrm{ha}^{-1}\right)$ e Piauí (26.335 kg ha' ${ }^{-1}$ ) (IBGE, 2010).

Um aspecto importante que deve ser considerado na produção da cultura da melancia é a marcha de absorção dos nutrientes, expressa na forma de curvas de resposta em função da idade das plantas, as mesmas informam os períodos em que elas absorvem os nutrientes em maiores quantidades, indicando, assim, as épocas em que a adição de nutrientes fazse necessária. Por isso, ela constitui ferramenta importantíssima para o manejo e fertilização das culturas.

Braga et al. (2008) analisando o crescimento da melancia Mickylee cultivada sob fertirrigação em estado do Nordeste brasileiro observaram que o maior acúmulo de massa seca da parte aérea ocorreu a partir dos 25 DAT com o início da frutificação, com os frutos participando com $63 \%$ da massa seca total acumulada; sendo os valores máximos de massa seca total da parte aérea, de folhas e de frutos, área foliar, taxa de crescimento absoluto, taxa de crescimento relativo, taxa assimilatória líquida e razão de área foliar $183,15 \mathrm{~g}$ planta $^{-1}, 51,86 \mathrm{~g}_{\text {planta }}{ }^{-1}, 117,03 \mathrm{~g}$ planta $^{-1}, 1,13 \mathrm{~m} 2$ planta $^{-1}, 6,96$ g planta $^{-1} \mathrm{dia}^{-1}, 0,16 \mathrm{~g} \mathrm{~g}^{-1} \mathrm{dia}^{-1}, 13,23 \mathrm{~g} \mathrm{~m}^{-2} \mathrm{dia}^{-1} \mathrm{e}$ $0,080 \mathrm{~m}^{2} \mathrm{~g}^{-1}$, respectivamente.

Grangeiro e Cecílio Filho, (2004a) trabalhando com o híbrido de melancia Tide, observaram que a parte vegetativa representada pelas folhas e caule teve participação maior na massa de matéria seca total até 48 DAT. Após esse período, ocorreu um correspondente aumento da participação dos frutos. Essa alteração, acontecida com o ingresso da planta no processo reprodutivo, proporciona maior translocação de carboidratos e de outros compostos das folhas para os frutos, como decorrência da predominância da fase reprodutiva sobre a fase vegetativa. No final do ciclo, a contribuição média da parte vegetativa foi de $34,4 \%$ e dos frutos, de $65,6 \%$. No híbrido de melancia Tide, no mesmo experimento, essa participação foi, respectivamente, de 31 e $69 \%$ na parte vegetativa e nos frutos (GRANGEIRO; CECÍLIO FILHO, 2004b).

Neste contexto, o objetivo do presente trabalho foi avaliar o crescimento e acúmulo de macronutrientes por cultivares de melancia no estado de Pernambuco.

\section{MATERIAL E MÉTODOS}

O experimento foi conduzido na estação experimental de Bebedouro (Petrolina-PE) pertencente a Embrapa Semiárido. O experimento foi conduzido no período de setembro a dezembro de 2009. O solo das área experimental foi classificado como Argisolo VermelhoAmarelo Eutrófico (EMBRAPA, 1999). Da área experimental foram retiradas amostras de solo, cujo resultado da análise química é apresentado na Tabela 1.

Tabela 1. Resultado da análise de solo da área experimental na estação experimental de Bebedouro pertencente a Embrapa Semiárido, Petrolina, Pernambuco.

\begin{tabular}{lccccccr}
\hline Experimento & $\begin{array}{c}\mathrm{pH} \\
\text { (água } 1: 2,5)\end{array}$ & $\begin{array}{c}\mathrm{P} \\
\left(\mathrm{mgdm}^{-3}\right)\end{array}$ & $\mathrm{K}$ & $\mathrm{Ca}$ & $\begin{array}{c}\mathrm{Mg} \\
\mathrm{cmol}_{\mathrm{c}} \mathrm{dm}^{-3}\end{array}$ & $\mathrm{Na}$ & $\mathrm{Al}$ \\
\hline Petrolina-PE & 7,4 & 44,5 & 70,0 & 1,9 & 1,5 & 0,05 & 0,05 \\
\hline
\end{tabular}

O delineamento utilizado no experimento foi blocos casualizados completos, com quatro repetições em esquema fatorial 2 x 5 . Os tratamentos resultaram da combinação de duas cultivares de melancia (Quetzale e Shadow) e cinco épocas de coletas $(15,25,35,45$ e 55 dias após o transplantio-DAT). Em cada coleta foram utilizadas três plantas por repetição. A unidade experimental para o experimento foi constituída por três fileiras de plantas de 10,5 $\mathrm{m}$ de comprimento espaçadas de 2,0 x 0,50 m, perfazendo uma área total de $63,0 \mathrm{~m}^{2}$. As coletas de plantas foram realizadas na fileira central.

O preparo do solo constou de aração e gradagem, seguido do sulcamento em linhas, espaçadas de $2 \mathrm{~m}$ e com profundidade de $30 \mathrm{~cm}$, onde foram realizadas as adubações de fundação com base na análise do solo e recomendação de adubação para melancia segundo Cavalcanti (1998), sendo 
utilizados $30 \mathrm{~kg} \mathrm{ha}^{-1}$ de $\mathrm{N}, 120 \mathrm{~kg} \mathrm{ha}^{-1}$ de $\mathrm{P}_{2} \mathrm{O}_{5}$ e $60 \mathrm{~kg} \mathrm{ha}^{-1} \mathrm{de}$ $\mathrm{K}_{2} \mathrm{O}$, aplicado através da formulação comercial 06-24-12. As adubações de cobertura foram realizadas via água de irrigação, seguindo as recomendações da análise de solo e obedecendo às exigências nutricionais da planta em cada estádio de desenvolvimento. As quantidades aplicadas foram de $50 \mathrm{~kg} \mathrm{ha}^{-1}$ de $\mathrm{N}$ e $60 \mathrm{~kg} \mathrm{ha}^{-1}$ de $\mathrm{K}_{2} \mathrm{O}$, nas formas de nitrato de cálcio e sulfato de potássio. A semeadura foi realizada em bandejas de poliestireno expandido para 128 mudas, preenchidas com substrato comercial, nos quais permaneceram em casa de vegetação por período de 12 dias até o transplantio. O sistema de irrigação utilizado foi por gotejamento, sendo constituído de uma linha lateral por fileira de plantas com gotejadores tipo autocompensante, com vazão média de 1,5 L/h, espaçados de $0,50 \mathrm{~m}$ e distância entre linhas de $2 \mathrm{~m}$. As irrigações foram realizadas diariamente e as lâminas determinadas com base na evapotranspiração da cultura (ALLEN et al., 1998). O controle fitossanitário foi realizado de acordo com as recomendações técnicas adotadas na região para a cultura da melancia.

As coletas de plantas foram realizadas nos períodos pré-estabelecidos, geralmente na parte da manhã, para evitar que as plantas murchem até chegar ao laboratório. No laboratório as plantas foram separadas em parte vegetativa (folha + caules) e frutos, lavadas e colocadas separadamente, para secagem em estufa com circulação forçada de ar à temperatura de $65^{\circ} \mathrm{C}$, até atingir massa constante. Em função da massa seca das amostras foi determinado o acúmulo de massa seca em cada época de coleta, sendo os resultados expressos em $\mathrm{g}$ planta $^{-1}$. Em seguida, as amostras foram processadas em moinho e acondicionadas em recipientes fechados.

As análises químicas para a determinação dos teores de nutrientes presentes em cada fração foram realizadas nos extratos obtidos pela digestão sulfúrica (nitrogênio), nítricoperclórica (fósforo, potássio, cálcio, magnésio, zinco, ferro e manganês). O nitrogênio foi quantificado pelo método semimicro Kjeldahl, fósforo pelo método do complexo fosfomolíbdico em meio redutor, adaptado por Braga e Defelipo (1974), o potássio por fotometria de emissão de chama. O cálcio e magnésio, por espectrofotometria de absorção atômica (EMBRAPA, 1997).

Os resultados das análises forneceram as concentrações dos nutrientes (N, P, K, Ca e Mg.) e para se determinar a quantidade destes acumulados em cada fração da planta, foi multiplicada a concentração pela massa seca da referida fração, sendo que o acúmulo total na planta foi determinado através da soma do acúmulo das frações para cada nutriente.

Para a análise estatística, os dados foram submetidos às análises de variância, com o software SISVAR e de regressão com o software Tablecurve (JANDEL SCIENTIFIC, 1991). Na análise de regressão, os modelos foram escolhidos baseados na ocorrência biológica e na significância dos coeficientes de regressão tendo como variável independente à idade da planta, em dias, após o transplantio.

\section{RESULTADOS E DISCUSSÃO}

\section{Acúmulos de massa seca}

As cultivares de melancia Shadow e Quetzale apresentaram acúmulos de massa seca lento até os 25 DAT.
Após esse período há um aumento significativo na massa seca da planta inteira, atingindo o máximo estimado ao final do ciclo, sendo respectivamente para as cultivares Quetzale e Shadow de 452,1 e 497,1 g planta $^{-1}$ e de 383,8 e (Figura 1B e 1A). A cultivar Shadow, apresentou maior crescimento em relação à Quetzale, comprovado pelo maior acúmulo de massa seca pela planta.

Figura 1. Acúmulo de Massa seca Total (MST), Massa seca na Parte Aérea (MSPA) e Massa seca no Fruto (MSB) em melancia, cultivares Shadow (A) e Quetzale (B)
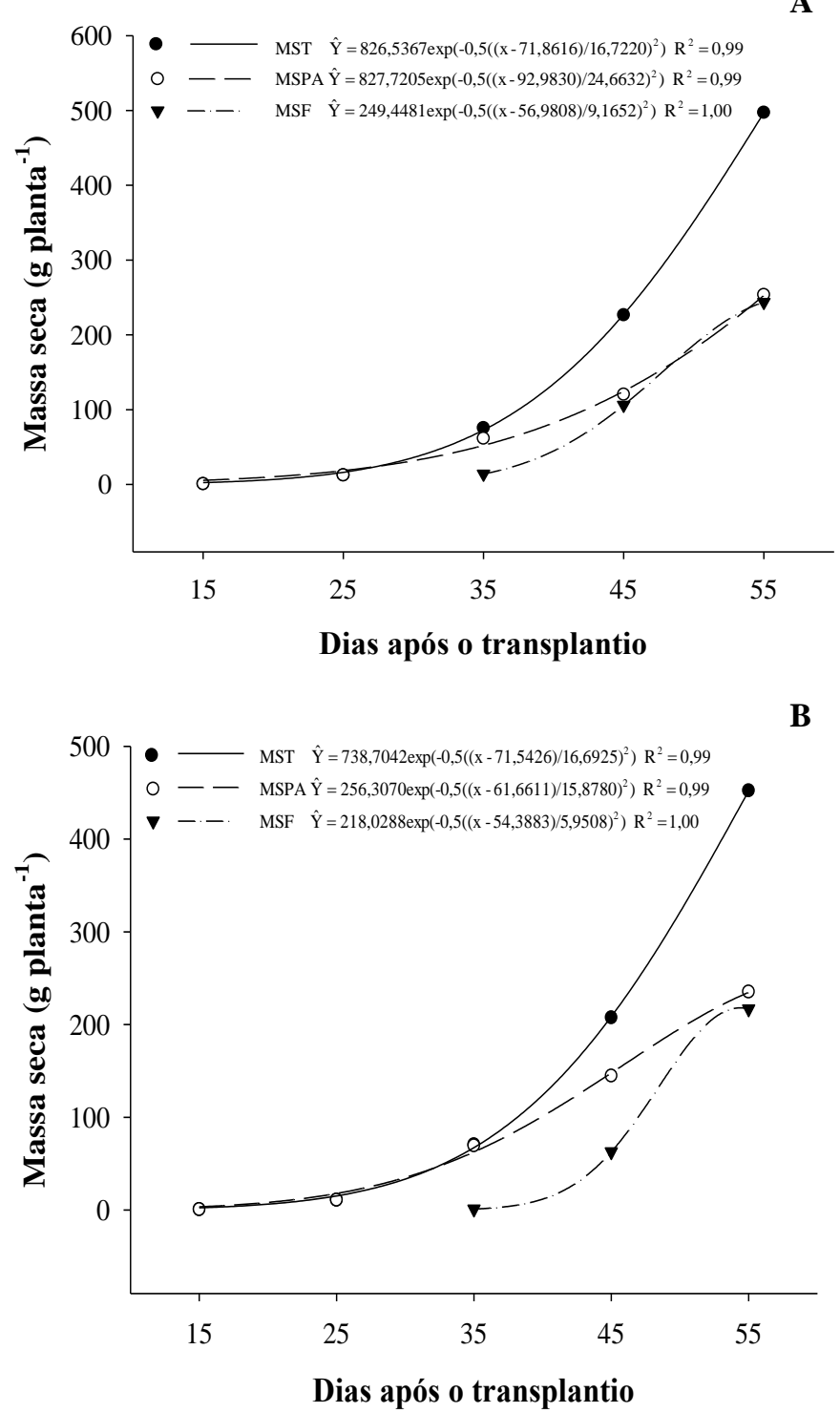

A cultivar Shadow tendeu a apresentar um ciclo maior, razão pelo qual apresentou um maior acúmulo de massa seca no final do ciclo. Grangeiro e Cecílio Filho (2005) obtiveram acúmulo máximo estimado de massa seca em melancia Shadow de 1.304,6 $\mathrm{g} \mathrm{planta}^{-1}$, obtida aos 68 DAT, em trabalho realizado no município de Borborema-SP.

Nogueira (2011), trabalhando com as cultivares Leopard e Quetzali observaram que o maior acúmulo de matéria seca foi verificado na metade do ciclo de ambas cultivares analisadas. Considerando uma curva média para massa seca da parte vegetativa obteve-se um maior acúmulo de massa seca em favor dos frutos comprovando que os 
mesmos comportaram-se como dreno principal da planta, desde o início da frutificação até a sua colheita.

O acúmulo máximo de massa seca estimado na parte aérea ocorreu respectivamente para Quetzale e Shadow aos 55 $\left(234,3 \mathrm{~g} \mathrm{planta}^{-1}\right)$ e $\left(253,0 \mathrm{~g} \mathrm{planta}^{-1}\right)$. O maior acúmulo ocorreu no período de 45 a 55 DAT com taxas de 6,0 e 9,0 g planta $^{-1}$ dia $^{-1}$ na Quetzale e Shadow. (Figuras 1A e 1B). Ao final do ciclo (55 e 65 DAT), a parte aérea acumulou 52 e $51 \%$ da massa seca da planta para Quetzale e Shadow.

Quanto ao acúmulo máximo de massa seca estimado no fruto ocorreu respectivamente para Quetzale e Shadow aos 55 DAT $\left(216,9\right.$ g planta $\left.^{-1}\right)$ e $\left(236,1\right.$ g planta $\left.^{-1}\right)$. (Figuras $1 \mathrm{~A} \mathrm{e}$ 1B). Ao final do ciclo (55 e 65 DAT), o fruto acumulou 48 e $49 \%$ da massa seca da planta para Quetzale e Shadow.

$\mathrm{O}$ ingresso da planta no processo reprodutivo proporciona maior translocação de carboidratos e outros compostos das folhas para os frutos, como decorrência da predominância da fase reprodutiva sobre a fase vegetativa (MARSCHNER, 1995). Fato semelhante foi observado por Souza (1976) em morangueiro, Fayad (1998) em tomateiro e Grangeiro e Cecílio Filho (2002) em melancieira.

\section{Acúmulos de macronutrientes}

A taxa de absorção dos macronutrientes pelas plantas de melancia foi baixa nos primeiros 25 DAT, coincidindo com o período de menor acúmulo de massa seca. Os maiores incrementos aconteceram após a frutificação. A ordem decrescente de acúmulo para as cultivares Quetzale e Shadow ao final do ciclo foi: $\mathrm{K}>\mathrm{N}>\mathrm{Ca}>\mathrm{P}>\mathrm{Mg}$.

$\mathrm{O}$ nitrogênio foi o segundo nutriente mais absorvido, com maior demanda ocorrida no período de 35 a 55 DAT, época que coincidiu com grande desenvolvimento da parte aérea. Os máximos estimados foram para Quetzale e Shadow de 7,84 g planta ${ }^{-1}$ (55 DAT) e 6,52 g planta ${ }^{-1}$ (55 DAT). (Figuras 2A e 2B).

$\mathrm{O}$ acúmulo de nitrogênio na parte aérea (NPA), assim como, observado na matéria seca total (Figura 2) foi lento durante os primeiros 25 DAT. A partir dessa idade observou-se um incremento significativo no acúmulo deste nutriente, atingindo valores máximos estimados de 5,07 (55 DAT) e 3,82 g planta $^{-1}$ (55 DAT) para Quetzale e Shadow. (Figuras 2A e 2B). A maior demanda ocorreu no período de 45 a 55 DAT, com taxas médias de acúmulo respectivamente para Quetzale e Shadow. No final do ciclo a contribuição da parte aérea foi de 65 e $59 \%$ do $\mathrm{N}$ da massa seca da planta para Quetzale e Shadow. (Figuras 2A e 2B). Grangeiro et al. (2005), trabalhando com a cultivar Shadow, observaram que o nitrogênio foi o segundo nutriente mais absorvido, apresentando maior demanda no período de 42 a 56 DAT, época que coincide com grande desenvolvimento da parte aérea, e o seu acúmulo máximo foi de 31,7 $\mathrm{g}_{\text {planta }}{ }^{-1}$, ocorrido aos 61 DAT. Comportamento semelhante foi verificado também por Grangeiro e Cecílio Filho (2004) e em outras espécies da mesma família, como melão (LIMA, 2001), pepino (SOLIS et al. 1988) e abobrinha (ARAÚJO et al. 2001 ). Na escala do ciclo da cultura, há, portanto, uma ligação entre a absorção de $\mathrm{N}$ e o crescimento em massa seca da planta (ANDRIOLO, 1999).

$\mathrm{O}$ acúmulo máximo de $\mathrm{N}$ estimado no fruto ocorreu respectivamente para Quetzale e Shadow aos 55 (2,75 g planta $\left.^{-1}\right)$ e $\left(2,70 \mathrm{~g} \mathrm{planta}^{-1}\right)$. A contribuição de massa seca do fruto no final do ciclo foi de 35 e $41 \%$ para Quetzale e Shadow. (Figuras 2A e 2B).
Figura 2. Acúmulo de Nitrogênio Total (NT), Nitrogênio na Parte Aérea (NPA) e Nitrogênio no Fruto (NF) em melancia, cultivares Shadow Petrolina-PE (A) e Quetzale (B).

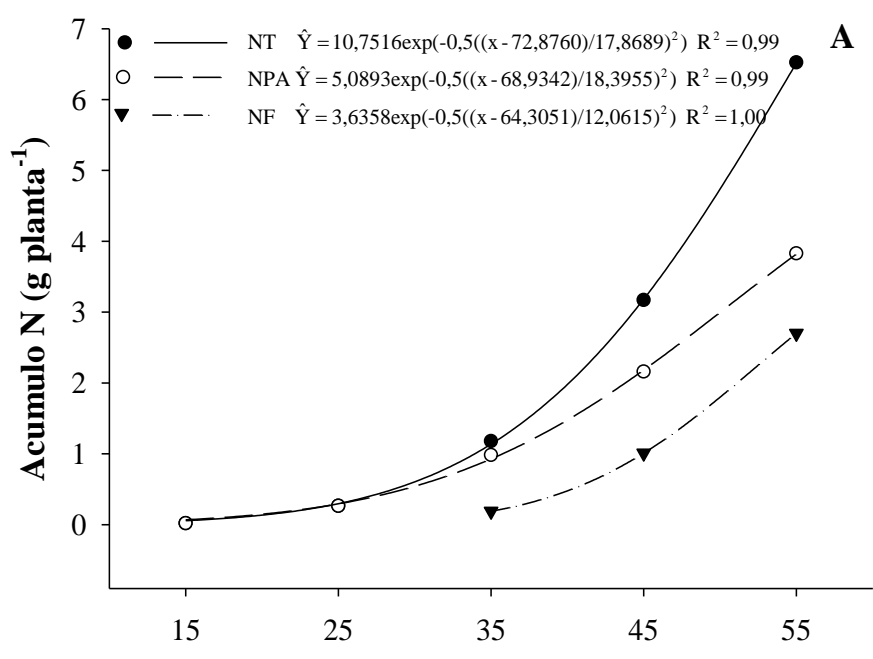

Dias após o transplantio

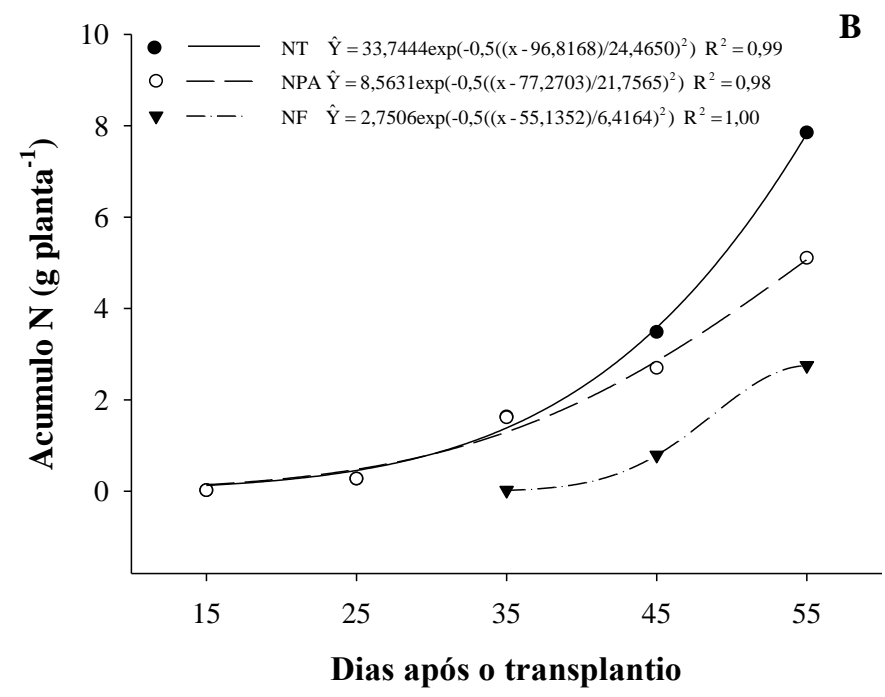

O fósforo ficou entre os macronutrientes acumulados em menor quantidade. Os valores máximos estimados foram obtidos aos 55 DAT, sendo de 2,06 g planta ${ }^{-1}$ e 2,06 g planta 1 , respectivamente para as cultivares Quetzale e Shadow. A maior demanda ocorreu no período de 45 a 55 DAT nas duas cultivares com taxa de $0,10 \mathrm{~g}$ planta $^{-1} \mathrm{dia}^{-1}$ para Quetzale e Shadow.

O acúmulo de $\mathrm{P}$, na parte aérea (PPA) foi crescente sendo que o máximo estimado variou conforme o experimento e a cultivar de melancia. Os máximos estimados foram para Quetzale e Shadow de 1,07 e 0,98 g planta ${ }^{-1}$ (55 DAT). (Figura 3). A maior demanda ocorreu no período de 45 a 55 DAT, com taxas médias de acúmulo respectivamente para Quetzale e Shadow de $0,03 \mathrm{~g}$ planta $^{-1} \mathrm{dia}^{-1}$. A participação da parte aérea no acúmulo total de $\mathrm{P}$ no final do ciclo foi de aproximadamente 52 e $48 \%$ nas cultivares Quetzale e Shadow. (Figuras 3A e 3B).

Nas cultivares Quetzale e Shadow o acúmulo máximo de $\mathrm{P}$ estimado no fruto ocorreu respectivamente aos 55 DAT $\left(0,98 \mathrm{~g} \mathrm{planta}^{-1}\right)$ e $\left(1,08 \mathrm{~g} \mathrm{planta}^{-1}\right)$. (Figuras $3 \mathrm{~A}$ e 3B). A maior demanda ocorreu no período de 45 a 55 DAT, 
com taxas médias de acúmulo respectivamente para Quetzale e Shadow de 0,10 e $0,04 \mathrm{~g}_{\text {planta }^{-1}} \mathrm{dia}^{-1}$.

A participação do fruto no acúmulo total de $\mathrm{P}$ foi de aproximadamente 48 e $52 \%$ nas cultivares Quetzale e Shadow. Vidigal et al. (2009) em um experimento realizado em Jaíba (MG), para avaliar o crescimento e o acúmulo de nutrientes pela melancia, cv. Crimson Sweet

observaram que a planta acumulou $\mathrm{P}$ lentamente até os 61 DAS, intensificando-o a partir de então, atingindo a quantidade máxima estimada de 3,62 g planta $^{-1}$ aos 89 DAS, quando parte aérea e frutos acumularam 32, 16 e 55\%, respectivamente. O período de maior acúmulo de $\mathrm{P}(98 \%)$ foi de 68 a 89 DAS, coincidindo com o período de maior acúmulo de maior acúmulo de matéria seca de frutos, ou seja, período de formação dos frutos. Diferentemente do que encontramos nesta pesquisa, o $\mathrm{P}$ foi absorvido lentamente, até aos 35 DAT intensificando a partir dai e indo até aos 55 atingindo a quantidade máxima estimada de 2,10 $\mathrm{g} \mathrm{planta}^{-1}$ aos 55 DAT na cultivar Shadow.

Figura 3. Acúmulo de Fosforo Total (PT), Fosforo na Parte Aérea (PPA) e Fosforo no Fruto (PF) em melancia, cultivares Shadow (A) e Quetzale (B).

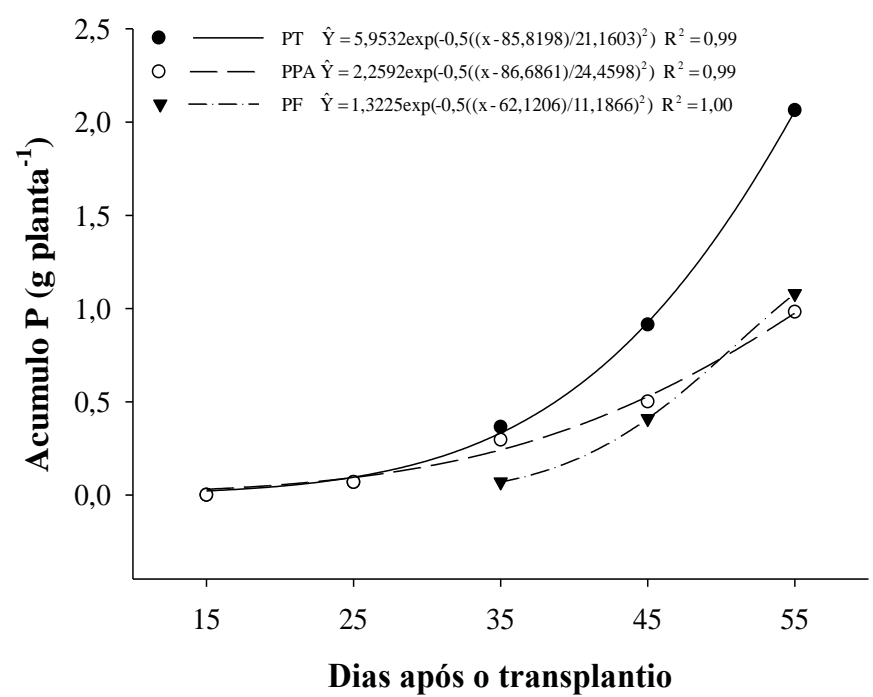

B

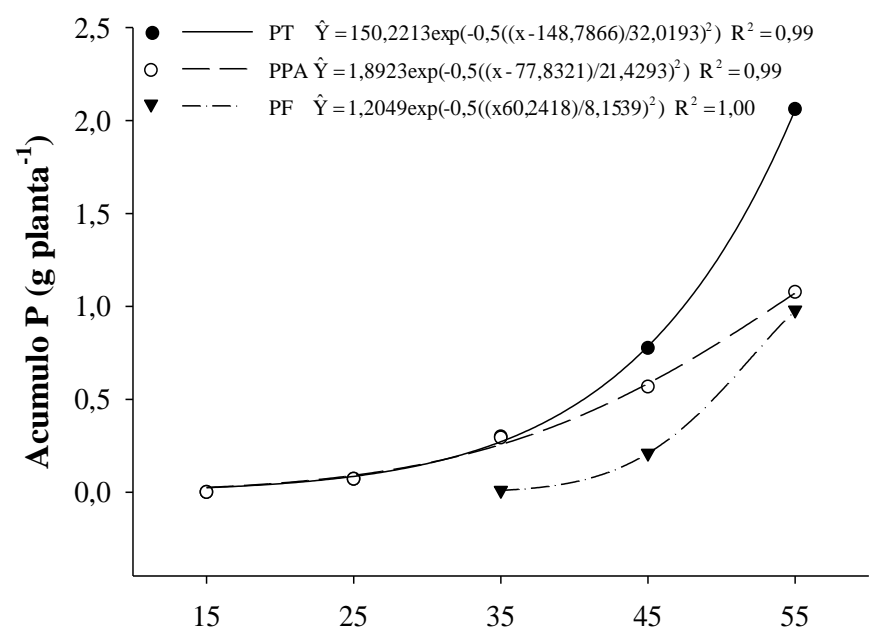

Dias após o transplantio
O potássio foi o nutriente mais absorvido pelas cultivares de melancia Quetzale e Shadow, com acúmulo máximo estimado de 25,61 e 20,51 g planta ${ }^{-1}$ (55 DAT), tendo a maior demanda deste nutriente ocorrido no período de 45 a 55 DAT nas duas cultivares com 0,96 e 1,0 $\mathrm{g} \mathrm{planta}^{-1} \mathrm{dia}^{-}$ ${ }^{1}$ (Quetzale e Shadow). (Figura 4). Este resultado concorda e é similar ao de vários outros trabalhos, os quais versam sobre exigência nutricional em cucurbitáceas. Vidigal et al. (2009), trabalhando com a cultivar Crimson Sweet, observaram que a quantidade de K acumulada foi estimada em 24,19 g planta $^{-1}$, aos 89 DAS, sendo que a maior parte do K $(98,14 \%)$ foi acumulada no período de 61 a 89 DAS. As folhas, o caule e os frutos acumularam 24, 20 e $56 \%$ do total de $\mathrm{K}$ acumulado pela planta. Muito embora o $\mathrm{K}$ não faça parte de nenhum composto orgânico da planta, ele desempenha diversas funções importantes, como na fotossíntese, na síntese de proteínas e na ativação enzimática, além do transporte de carboidratos (TAIZ; ZEIGER, 1991; MARSCHNER, 1995), o que, neste caso, explicaria o maior acúmulo nos frutos, como observado por Grangeiro; Cecílio Filho (2004, 2005) para melancia. Isso também ocorre em outras hortaliças fruto (SOLIS et al. 1988; LIMA, 2001; ARAÚJO et al. 2001; FAYAD et al. 2001; VIDIGAL et al. 2007).

$\mathrm{O}$ acúmulo de $\mathrm{K}$, na parte aérea (KPA) foi crescente onde os máximos estimados foram para Quetzale e Shadow de 9,93 e 10,48 $\mathrm{g} \mathrm{planta}^{-1}$ (55 DAT). A maior demanda ocorreu nos períodos de 35 a 45 e 45 a 55 DAT, com taxas médias de acúmulo de $0,4 \mathrm{~g}_{\text {planta }}{ }^{-1} \mathrm{dia}^{-1}$ nas duas cultivares Quetzale e Shadow. De acordo com os valores observados ao final do ciclo, o $\mathrm{K}$ presente na parte aérea foi de aproximadamente 39 e $51 \%$ para Quetzale e Shadow. (Figuras 4A e 4B).

Os máximos acúmulos estimados de $\mathrm{K}$ no fruto foram observados na Quetzale e Shadow com 15,69 e 10,04 (55 DAT) e 6,31 g planta ${ }^{-1}$ (59 DAT). No final do ciclo da cultura o potássio acumulado no fruto foi de aproximadamente 61 e 49\%, para Quetzale e Shadow. As maiores demandas de $\mathrm{K}$ pelo fruto situaram-se no período de 45 a 55 DAT para Quetzale e Shadow com taxa de 1,0 e 0,4 g planta $^{-1}$. (Figuras 4A e 4B).

Devido ao elevado acúmulo de massa seca pelos frutos, estabelecendo uma correspondente demanda por nutrientes, pode-se inferir, a partir das curvas de acúmulo (Figura 4) que houve forte translocação de $\mathrm{K}$ das folhas para os frutos. Resultados semelhantes foram verificados por Del Rio et al. (1994), em diversas cultivares de melancia, quando observaram redução do teores de $\mathrm{K}$ nas folhas com $\mathrm{o}$ desenvolvimento dos frutos; de modo semelhante Araújo et al. (2001) verificaram redução no acúmulo de $\mathrm{P}, \mathrm{K}, \mathrm{Ca}$ e $\mathrm{Mg}$ na parte vegetativa de abobrinha durante a frutificação.

A elevada participação dos frutos no conteúdo de $\mathrm{K}$ na planta concorda com outros trabalhos encontrados em literatura que relatam a forte associação entre a maior demanda de $\mathrm{K}$ com a elevada produtividade e qualidade dos frutos de melancia e melão (SUNDSTROM; CARTER, 1983; ZENG; JIANG, 1989; SIMONNE et al., 1992; ZHU et al., 1996; GRANGEIRO; CECÍLIO FILHO, 2004). 
Figura 4. Acúmulo de Potássio Total (KT), Potássio na Parte Aérea (KPA) e Potássio no Fruto (KF) em melancia, cultivares Shadow (A) e Quetzale (B)..

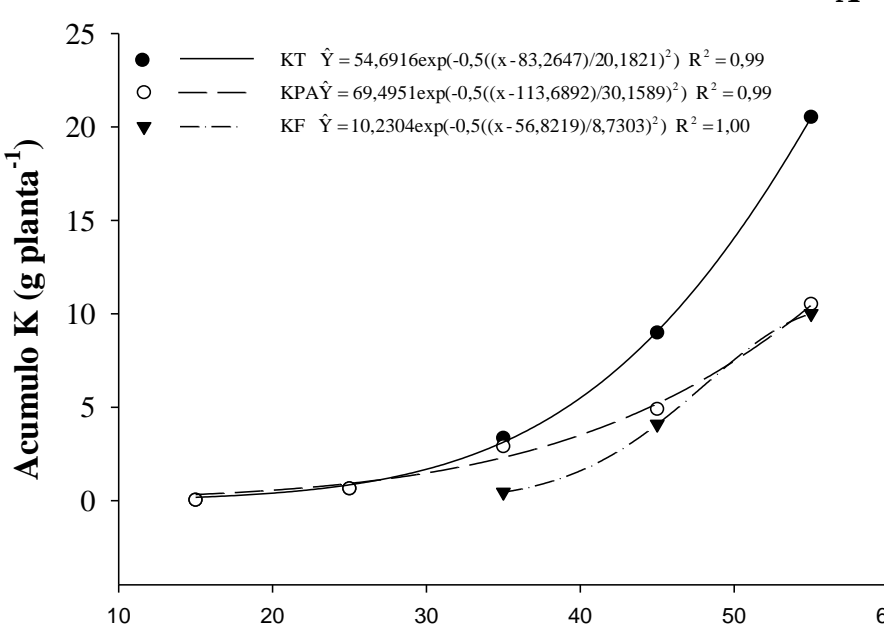

Dias após o transplantio

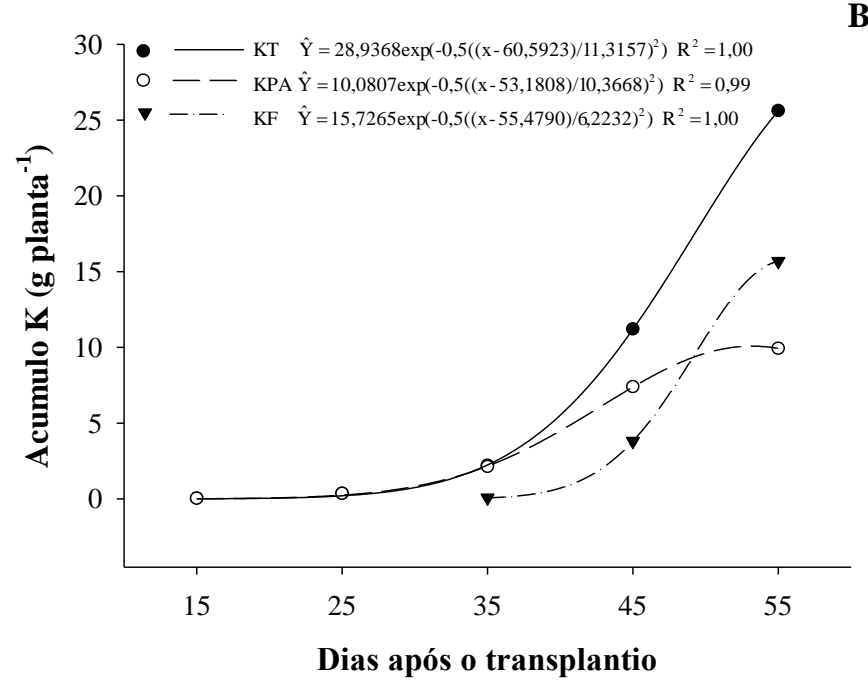

O cálcio seguiu o comportamento apresentado por outros trabalhos com melancia, sendo absorvido em quantidade inferior ao $\mathrm{K}$ e $\mathrm{N}$. O acúmulo do nutriente $\mathrm{Ca}$ foi lento durante os primeiros 25 DAT (Figura 5). A partir dessa idade observou-se um incremento significativo no acúmulo deste nutriente, atingindo valores máximos estimados de 8,65 e 6,13 $\mathrm{g} \mathrm{planta}^{-1}$ aos 55 DAT para Quetzale e Shadow. (Figuras 5A e 5B). A maior demanda deste nutriente ocorreu no período de 45 a 55 DAT nas duas cultivares. (Figura 4).

$\mathrm{O}$ acúmulo de $\mathrm{Ca}$ na parte aérea da melancia foi baixo nos primeiros 25 DAT (Figuras 5A e 5B), coincidindo com o período de menor acúmulo de massa seca total (Figura 5). Os maiores incrementos de $\mathrm{Ca}$ foram registrados a partir dos 35 DAT, onde os máximos estimados foram para Quetzale e Shadow de 26,10 e 4,37 g planta $^{-1}$ (90 e 55 DAT). No final do ciclo, o Ca presente na massa seca da parte aérea foi de aproximadamente 77 e $71 \%$ para Quetzale e Shadow. (Figuras $5^{\mathrm{a}}$ e 5B). Este padrão de distribuição do Ca em favor da parte aérea resulta do mesmo ser transportado quase que exclusivamente pelo xilema e praticamente não redistribuído. Outro fator que favorece essa situação é a competição entre K e Ca que se faz, também, dentro da planta (MALAVOLTA et al. 1997). O maior fluxo de potássio para o fruto de melancia concorre para diminuir a presença de cálcio. Comportamento semelhante foi verificado para outras hortaliças e melão (SANCHEZ et al., 1998). Grangeiro; Cecílio (2005) em experimento com melancia sem sementes, híbrido Nova, em um Argissolo Vermelho-Amarelo Distrófico, observaram que o cálcio foi o terceiro nutriente mais acumulado pela planta, com máximo de 5,22 $\mathrm{g}_{\text {planta }}{ }^{-1}$. A maior demanda ocorreu no período de 45 a 60 DAT. Entre os nutrientes, foi o que apresentou maior acúmulo nas folhas, sendo estas responsáveis por $66 \%$, caule + ramos por $23 \%$ e os frutos por apenas $11 \%$.

O acúmulo máximo de Ca estimado no fruto ocorreu respectivamente para Quetzale e Shadow aos 55 (1,99 g planta $\left.^{-1}\right)$ e $\left(1,73 \mathrm{~g} \mathrm{planta}^{-1}\right)$. A contribuição de Ca na massa seca do fruto no final do ciclo foi de 23 e $29 \%$ para Quetzale e Shadow, (Figuras 5A e5B).

Figura 5. Acúmulo de Cálcio Total (CaT), Cálcio na Parte Aérea (CaPA) e Cálcio no Fruto $(\mathrm{CaF})$ em melancia, cultivares Shadow (A) e Quetzale (B).
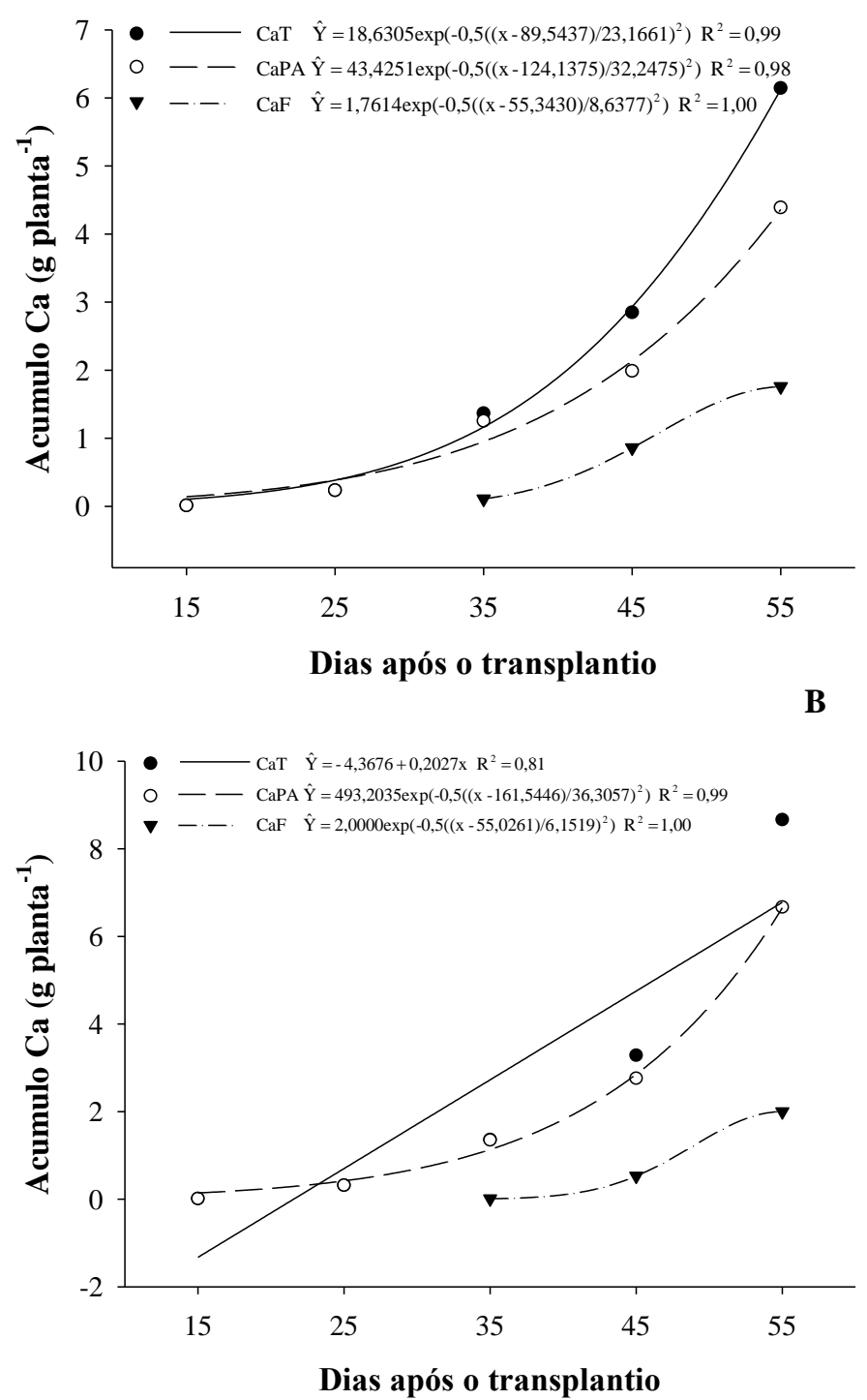

O acúmulo de $\mathrm{Mg}$ total ocorreu até o final do ciclo, atingindo o máximo estimado de 1,60 e 1,03 g planta $^{-1}$, aos 55 DAT para Quetzale e Shadow. As maiores demandas ocorreram no período de 45 a 55 DAT com taxas de 0,10 e 
$0,03 \mathrm{~g} \mathrm{planta}^{-1} \mathrm{dia}^{-1}$ para Quetzale e Shadow. O acúmulo de $\mathrm{Mg}$ na parte aérea foi reduzido até os 25 DAT, a partir de então foi intensificado, alcançando o máximo estimado, aos 55 DAT, igual a 0,93 e $0,82 \mathrm{~g} \mathrm{planta}^{-1}$ para Quetzale e Shadow. (Figura 6).

$\mathrm{O}$ acúmulo de $\mathrm{Mg}$ pelos frutos, determinado a partir dos 35 DAT, foi pequeno, inicialmente, e teve seu crescimento acelerado aos 45 DAT, quando atingiu acúmulos máximas estimados de 0,67 e 0,22 $\mathrm{g} \mathrm{planta}^{-1}$, aos 55 DAT para Quetzale e Shadow. (Figura 6). Os frutos acumularam 42 e $20 \%$ do total de $\mathrm{Mg}$ acumulado pela planta. Grangeiro; Cecílio, (2005), com a melancia sem sementes, híbrido Nova, verificaram que o total acumulado de $\mathrm{Mg}$ na planta foi de 2,67 g planta $^{-1}$, com maior demanda no período de 45 a 60 DAT, coincidindo com o maior incremento de massa seca na planta. As participações das folhas, caule + ramos e frutos foram, respectivamente, de 45; 28 e $27 \%$. As quantidades de $\mathrm{Mg}$ acumuladas no caule + ramos e frutos, a partir de 60 DAT foram muito semelhantes e, no final do ciclo, ambos segmentos apresentaram $0,74 \mathrm{~g} \mathrm{planta}^{-1}$.

A partir dos 45 DAT, o caule + ramos apresentou taxa de acúmulo constante, de aproximadamente $0,3 \mathrm{~g}_{\text {planta }}{ }^{-1}$. O magnésio, semelhante ao ocorrido com o cálcio, apresentou acúmulos elevados na parte aérea, muito provavelmente, por fazer parte da molécula de clorofila. De acordo com Marschner (1995) dependendo do "status" de Mg na planta, de 6 a $25 \%$ do magnésio total pode estar ligado à molécula de clorofila, enquanto, outros 5 a $10 \%$ ligados à pectatos na parede celular ou depositado como sal solúvel no vacúolo.

Figura 6. Acúmulo de Magnésio Total (MgT), Magnésio na Parte Aérea (MgPA) e Magnésio no Fruto (MgF) em melancia, cultivares Shadow (A) e Quetzale (B).

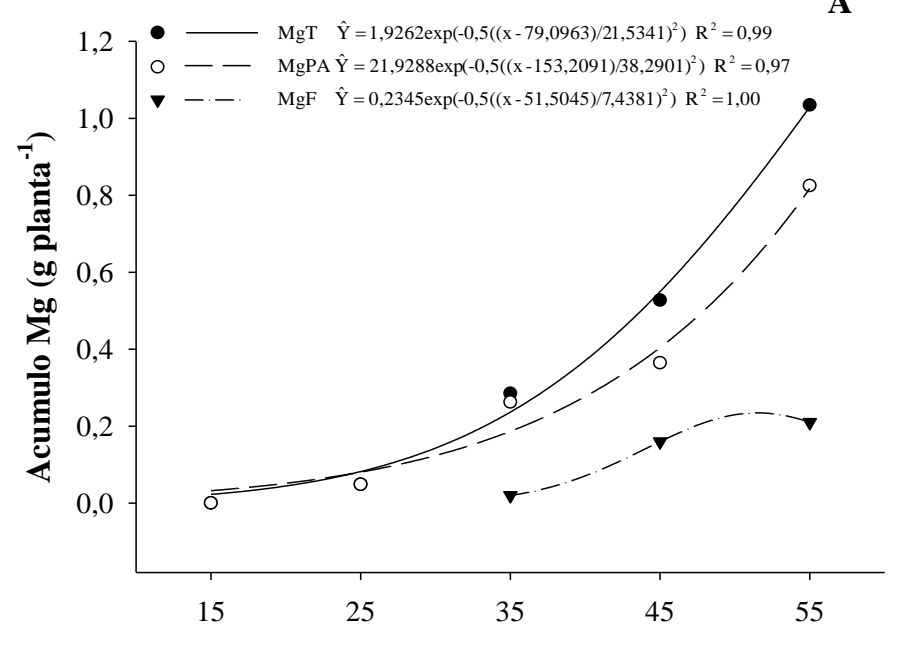

A

Dias após o transplantio

Tabela 2. Exportação de macronutrientes pelo fruto de melancia, cultivar Quetzale. Petrolina, Pernambuco.

\begin{tabular}{|c|c|c|c|c|c|c|}
\hline \multirow{2}{*}{ Local } & \multicolumn{5}{|c|}{ Exportação de nutrientes $\left(\mathrm{kg} \mathrm{ha}^{-1}\right)$} & \multirow{2}{*}{$\begin{array}{l}\text { Produtividade } \\
\qquad\left(\mathrm{t} \mathrm{ha}^{-1}\right)\end{array}$} \\
\hline & $\mathrm{N}$ & $\mathrm{P}$ & $\mathrm{K}$ & $\mathrm{Ca}$ & $\mathrm{Mg}$ & \\
\hline Petrolina-PE & 27,5 & 10,0 & 156,8 & 20,0 & 6,7 & 28,0 \\
\hline
\end{tabular}

Tabela 3. Exportação de macronutrientes pelo fruto de melancia, cultivar Shadow. Petrolina- Pernambuco.

\begin{tabular}{lcccccc}
\hline \multirow{2}{*}{ Local } & & \multicolumn{2}{c}{ Exportação de nutrientes $\left(\mathrm{kg} \mathrm{ha}^{-1}\right)$} & \multicolumn{3}{c}{$\begin{array}{c}\text { Produtividade } \\
\left(\mathrm{t} \mathrm{ha}{ }^{-1}\right)\end{array}$} \\
\cline { 2 - 7 } & $\mathrm{N}$ & $\mathrm{P}$ & $\mathrm{K}$ & $\mathrm{Ca}$ & $\mathrm{Mg}$ & \\
\hline Petrolina-PE & 18,0 & 7,2 & 66,7 & 11,7 & 6,7 & 26,0 \\
\hline População de 10.000 plantas ha $^{-1}$. & & & & &
\end{tabular}

Revista Verde, v.11, n.4, p.17-25, 2016

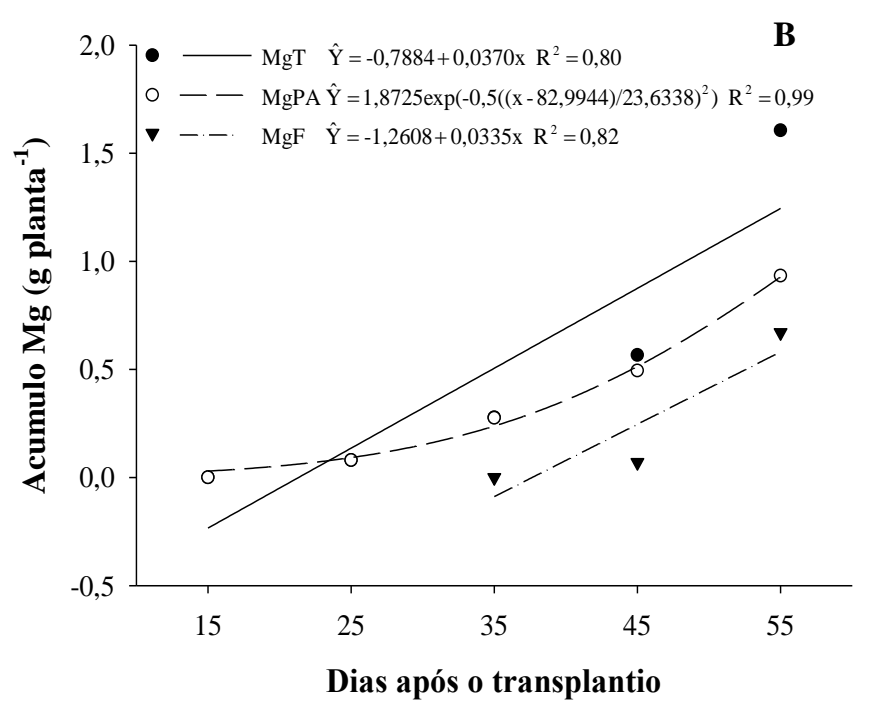

\section{Exportação de nutrientes}

Nas cultivares Quetzale e Shadow a ordem decrescente de exportação de nutrientes pelos frutos no momento da colheita foi de: $\mathrm{K}>\mathrm{N}>\mathrm{Ca}>\mathrm{P}>\mathrm{Mg}$. Sendo que as quantidades exportadas para Quetzale foram $27,5 \mathrm{~kg} \mathrm{ha}^{-1} \mathrm{de}$ $\mathrm{N} ; 10,0 \mathrm{~kg} \mathrm{ha}^{-1}$ de P; $156,8 \mathrm{~kg} \mathrm{ha}^{-1}$ de $\mathrm{K} ; 20,0 \mathrm{~kg} \mathrm{ha}^{-1}$ de Ca; $6,7 \mathrm{~kg} \mathrm{ha}^{-1} \mathrm{de} \mathrm{Mg}$; Na Shadow de 18,0 kg ha-1 de N; 7,2 kg $\mathrm{ha}^{-1}$ de P; 66,7 $\mathrm{kg} \mathrm{ha}^{-1}$ de $\mathrm{K} ; 11,7 \mathrm{~kg} \mathrm{ha}^{-1} \mathrm{de} \mathrm{Ca} ; 6,7 \mathrm{~kg} \mathrm{ha}^{-1} \mathrm{de}$ Mg. (Tabelas 2 e 3).

Grangeiro e Cecilio Filho (2004), para cultivar Tide obtiveram as seguintes quantidades de $\mathrm{N}, \mathrm{P}, \mathrm{K}, \mathrm{Ca}, \mathrm{Mg}$ e $\mathrm{S}$ exportadas pelos frutos 106,$4 ; 11,1 ; 118,0 ; 4,3 ; 6,8$ e 6,0 $\mathrm{kg} / \mathrm{ha}$, respectivamente. Em Shadow os valores foram na mesma ordem de 47;2,8;104,4;4,6;5,1 e 3,2 kg ha ${ }^{-1}$ (GRANGEIRO; CECILIO FILHO, 2005). As quantidades de nutrientes exportadas pelos frutos, portanto, representam importante componente de perdas de nutrientes do solo, que deverão ser restituídos, enquanto os nutrientes contidos na parte aérea podem ser incorporados ao solo dentro de um programa de reaproveitamento de restos culturais. 


\section{CONCLUSÕES}

A melamcia, cvs. Quetzale e Shadow apresentaram crescimento inicial lento, intensificando a partir dos 25 dias após o transplantio;

Maiores incrementos na matéria seca total, da parte aérea e do fruto ocorreram no período de 45 a 55 DAT;

Os macronutrientes foram absorvidos pela melancia na seguinte ordem: $\mathrm{K}>\mathrm{N}>\mathrm{Ca}>\mathrm{P}>\mathrm{Mg}$; para Quetzale e Shadow.

\section{REFERÊNCIAS}

ANDRIOLO, J.L. Fisiologia das culturas protegidas. Santa Maria, Editora da UFSM, 1999. 142 p.

ARAÚJO, W.F. BOTREL, T.A. CARMELLO, Q.A.C., SAMPAIO, R.A.; VASCONCELOS MRB. 2001. Marcha de absorção de nutrientes pela cultura da abobrinha conduzida sob fertirrigação. In: Folegatti, MV; Casarini, E; Blanco, FF; Brasil, RPC \& Resende, RS (Coord.) Fertirrigação: flores, frutas e hortaliças. Guaíba, Livraria e Editora Agropecuária, v.1, p.67-77.

ALLEN, R. G.; PEREIRA, L. S.; RAES, D.; SMITH, M. Crop evapotranspiration guidelines for computing crop water requirements. Rome: FAO, 1998. 297 p.

ARAÚJO, J. L. P.; ARAÚJO, E. P. Análise das relações de troca da melancia produzida na região do Submédio São Francisco. In: CONGRESSO BRASILEIRO DE FRUTICULTURA, 20, ANNUAL MEETING OF THE INTERAMERICAN SOCIETY FOR TROPICAL HORTICULTURE; 54, 2008, Vitória. Frutas para todos: estratégias, tecnologias e visão sustentável: Anais... Vitória: INCAPER: Sociedade Brasileira de Fruticultura, 2008. 1 DVD.

BRAGA, D. F.; NEGREIROS, M. Z.; LOPES, W.; TEÓFILO, T. M. S.; FREITAS, F.C.L.; GRANGEIRO, L. C.; ALVES, S. S. V. Crescimento de melancia „Mickylee ${ }^{c e}$ cultivada sob fertirrigação. Horticultura Brasileira, Brasília, DF, v. 26, n. 2, p. 5119-5124, (Suplemento-CD Rom), jul/ago, 2008.

BRAGA, J.M.; DEFELIPO, B.V. Determinação espectrofotométrica de fósforo em extratos de solo e material vegetal. Revista Ceres, Viçosa, v.21, p.73-85, 1974.

CAVALCANTI, F. J. A. C. (Coord.). Recomendação de adubação para o Estado de Pernambuco $2^{\circ}$ aproximação. Recife: IPA, 1998. 198 p.

DEL RIO, A.; LOPEZ-CANTARERO, I.; ROMERO, L.; SANCHEZ, A.; LORENTE, F.A.; VALENZUELA, J.L. Foliar diagnosis: vegetative index for several cultivars of watermelon. Communications in Soil Science and Plant Analysis, v.25, n.9-10, p.1629-1640, 1994.

EMBRAPA. Centro Nacional de Pesquisa de Solos (Rio de Janeiro, RJ). Manual de métodos de análise de solo. 2.ed.rev.atual. Rio de Janeiro, 1997. 212p. (EMBRAPACNPS. Documentos, 1).
EMBRAPA. Sistema Brasileiro de Classificação de Solos. Rio de Janeiro: Embrapa Solos. 412p. 1999.

EMBRAPA, Manual de análises químicas de solos, plantas e fertilizantes. Brasília. Embrapa Comunicação para Transferência de Tecnologia. 370p. 1999.

FAYAD, J.A. Absorção de nutrientes, crescimento e produção do tomateiro cultivado em condições de campo e estufa. 81 f. Dissertação (Mestrado em Fitotecnia) Universidade Federal de Viçosa, Viçosa. 1998

FAYAD, J.A., FONTES, P.C.R., CARDOSO, A.A., FINGER LF; FERREIRA, F.A. (2001) Crescimento e produção do tomateiro cultivado sob condições de campo e de ambiente protegido. Horticultura brasileira, 19: 365-370.

FAO. FAO para estudantes - statistics - FAOSTATAgriculture. Disponível em:

<http://www.fao.org/corp/statistics/en/>. Acesso em: 09 de jun. de 2012.

SISVAR: a computer statistical analysis system. Ciência e Agrotecnologia (UFLA), v. 35, n.6, p. 1039-1042, 2011

GRANGEIRO, L.C.; CECÍlIO FILHO, A.B. Marcha de absorção de nutrientes pela cultura da melancia. In: REUNIÃO BRASILEIRA DE FERTILIDADE DO SOLO E NUTRIÇÃO DE PLANTAS 25., REUNIÃO BRASILEIRA SOBRE MICORRIZAS 9., SIMPÓSIO BRASILEIRO DE MICROBIOLOGIA DO SOLO 7., REUNIÃO BRASILEIRA DE BIOLOGIA DO SOLO 4., 2002, Rio de Janeiro. Anais... 1 CD-ROM.

GRANGEIRO, L.C.; CECÍlLIO FILHO, A.B Acúmulo e exportação de macronutrientes pelo híbrido de melancia Tide. Horticultura brasileira, 22: 93-97. 2004a

GRANGEIRO, L. C.; CECÍlLIO FILHO, A. B. Qualidade de frutos de melancia em função de fontes e doses de potássio. Horticultura Brasileira, Brasília, v. 22, n. 3, p. 647-650. 2004b.

GRANGEIRO, L. C.; CECÍllO FILHO, A, B. Acúmulo e exportação de nutrientes pela melancia sem sementes, Hibrido Shadow. Cientifica, Jaboticabal, v. 33, n. 1, p. 69-74, 2005 a.

GRANGEIRO, L.C.; CECÍlIO FILHO AB Acúmulo e exportação de macronutrientes em melancia sem sementes. Horticultura brasileira, 23: 763-767.2005b.

IBGE. Produção Agrícola Municipal - culturas temporárias e permanentes. 2010, vol. 37. Disponível em:<http://www.ibge.gov.br/home/estatistica/economia/pam/ 2010 /PAM2010Publicacaocompleta.pdf>. Acesso em: 13 de abril de 2012.

JANDEL SCIENTIFIC. Table curve: curve fitting software. Corte Madera, CA: Jandel Scientific, 1991.280p

LIMA. A.A. Absorção e eficiência de utilização de nutrientes por híbridos de melão (Cucumis melo L.). Tese de mestrado. Fortaleza, Universidade Federal do Ceará. 60p. 2001. 
MALAVOLTA E; VITTI GC; OLIVEIRA SA. 1997.

Avaliação do estado nutricional das plantas. Piracicaba, Potafós. 319p.

MARSCHNER, H. Mineral nutrition of higher plants. San Diego: Academic Press, 1995. 889 p.

NOGUEIRA, F. P. Produção, crescimento e marcha de absorção de nutrientes da Melancieira fertirrigada com doses crescentes de n e k,. 66 f. Dissertação (Mestrado em Irrigação e Drenagem) - Federal Rural do Semiárido - UFERSA, Mossoró-RN. 2011.

ROCHA, M. R. Sistemas de cultivo para a cultura da melancia. 2010. 76f. Dissertação (mestrado em ciência do solo) Universidade Federal de Santa Maria. Santa Maria - RS, 2010 .

SANCHEZ, L.R.; SIRONI, J.S.; CRESPO, J.A.P.; PELLICER, C.; LOPEZ, M.D.G. Crecimiento y absorcion de nutrientes del melon bajo invernadero. Investigacion Agraria Produccion Proteccion Vegetales, Madrid, v.13, n.1-2, p.111120, 1998

SIMONNE, E.H.; MILLS, H.A.; SMITTLE, D.A. Ammonium reduces growth fruit yield and fruit quality of watermelon. Journal of Plant Nutrition, v.15, n.12, p.27272741, 1992.

SOLIS. F.A.M, HAAG. HP, MINAMI. K,; DIEHL. W.J. Nutrição de hortaliças. LVI Acumulação de nutrientes na cultura do pepino (Cucumis sativus L.) var. Aodai cultivado em condições de campo. Anais da Escola Superior de Agricultura Luiz de Queiroz, 39: 697-737. 1988.

SUNDSTROM, F.J.; CARTER, S.J. Influence of K and Ca on quality and yield of watermelon. Journal American Society for Horticultural Science, v.108, n.5, p.879-881, 1983.

SOUZA, A.F. Absorção de nutrientes por quatro cultivares de morangueiro (Fragaria spp).130 f. Dissertação (Mestrado em Solos e Nutrição de Planta) - Escola Superior "Luiz de Queiroz”, São Paulo. 1976

TAIZ, L.; ZEIGER, E. Plant Physiology. California, The Benjamin-Cummings Publishing Company, 559p. 1991

VIDIGAL, S.M., PACHECO, D.D.; FACION, C.E Crescimento e acúmulo de nutrientes pela abóbora híbrida tipo Tetsukabuto. Horticultura brasileira, 25: 375-380. 2007

VIDIGAL, S. M, PACHECO, D. D, COSTA, L. E.; FACION CE (2009)Crescimento e acúmulo de macro e micronutrientes pela melancia em solo arenoso. Ceres, 56(1): $112-118,2009$.

ZENG, Q.Y.; JIANG, X.L. Influence of potash fertilizers containing chlorine on the quality of watermelon. Soils, v.20, n.3, p.144-146, 1989. 